\title{
Jingdezhen Porcelain Making Tradition Inheritance of Inadaptability
}

\author{
Xiumei Wu \\ University of Jingdezhen Ceramic Institute of Design Art, Jingdezhen 333403, China
}

Keywords: Jingdezhen, the porcelain making, tradition inheritance and inadaptability.

\begin{abstract}
The beginning of the 20th century, China's political system and social environment have taken place in the most profound changes ever - overthrew the feudal system in one thousand and established the republic of China. The May 4th new culture movement and brought new thought system, and by the potential of refreshes the old ideology and old behaviors. In such a severe social turmoil in, however, traditional arts and crafts on the surface seems to have little change, generally in the tradition of the qing dynasty style and skill, and strong with the weak to continue development. But we can see the change from traditional culture, traditional craftsmanship complete metamorphosis will occur after 50 years of the 20th century, China's economy has great falls, and traditional handicraft instead of ups and downs, this is bound to cause our thinking: such a "different" mean? It means in the industrialized society, traditional handicrafts are bound to happen metamorphosis is objective law. And there are several factors that can contribute to the transformation of.
\end{abstract}

\section{Introduction}

Chinese arts and crafts a history of ten thousand years of uninterrupted, through ancient and modern, the evolution of the three big time, is facing the test of transformation and regeneration. "..., transformation does not mean that the die, but the regeneration in new ways. However, the transformation process is modified, after all. The fact is cruel principle of survival of the fittest applies not only to the nature, also apply to cultural industry...." My doctoral tutor professor, famous scholars various ge armoured in its "survival of the fittest, the transformation and regeneration of the traditional Chinese arts and crafts, the article carried on the analysis to the regeneration of traditional arts and crafts. We all see clearly that the 20th century one hundred years, traditional handicraft, starting from the late qing dynasty declining to liberation period has slumped to record lows. However, in the one hundred years, the inheritance of traditional craftsmanship issues is a major turning point, the historical evolution of traditional arts and crafts, law of development, the cultural connotation and research is increasingly prosperous, they are accompanied by social development and progress. Is closely related to the former and the social transformation and change, which is in the knowledge level, knowledge level, thought idea greatly enhance understanding of history and on the basis of the summary.

\section{The changes of the traditional culture and modern transformation of cultural conflict}

The late qing dynasty, from the beginning of the new ideas concerning the rise and pulled open the prelude to the modern transformation of Chinese traditional culture, the outbreak of the opium war started the modernization of traditional Chinese society, social and cultural double upheaval, the traditional culture of Chinese society in the historical vicissitude and the conflict of modern cultural transformation. Think craftsmanship in traditional ideology and culture heritage must be passed on to their offspring, to pass for a man not to wear female, the inside don't preach outside for the purpose, to start on the one hand, modern old text study the rise of the traditional thinking under the impetus of the new trend is broken, gong zizhen, wei yuan said the affairs and as the, kang youwei, tan sitong, liang qichao advocated more social reality so as to achieve "tool". Following the opium war, on the other hand, the western capitalist culture as capitalism powers of artillery, large-scale incoming goods and missionaries and Chinese have some contact with Chinese traditional culture to form the two 
forces: one is in, introduces western freedom, equality, fraternity and other democratic culture input; The second is the integration of modern culture not only appears between Chinese and western culture, but also within the traditional culture of Confucianism factions are integrated, reflects the era under the upheaval internal adjustment and adaptation of traditional culture, in the process of contact with western culture and traditional culture, the two cultures are contradictions and conflicts, in the government, within the literary intelligentsia have significant performance, in the folk, the lower the masses have strong prison. And also not pay any western culture between up and down a different attitude, in quite a few problems have shown mutual exclusion, as opposed to building railways, against the foreign church, in jingdezhen porcelain industry education problems also exist, porcelain industry school run by migration merger changed several times, ceramics are not interested in ceramic education, even to resist a new start-up. In 1915, unexpectedly into the elementary school stage a decorative porcelain vocational classes, fewer than 20 people, in 1924, when the sensitive elementary school also do a period porcelain professional class, number is very few.

In modern history, the conflicts between Chinese and western culture throughout the entire social life, everywhere at any time, such as a political movement, small such as customs. Therefore, studying abroad returned people with their conservative thinkers also will form two different cultural forces. This cultural transformation in social inevitable conflict, whether in their lifestyle, morality, concept, mental, emotional, and custom differences, also can have differences, to acceptance of western culture for the traditional thinkers there must be hard to accept the psychological and emotional factors of western culture, and is not all of western culture in essence, and dregs, etc. From the perspective of the process of modern history development, the trend of the conflicts between Chinese and western culture is not more and more sharp, but weakened, or even integration development, in the process, Chinese culture has declines, and one side, also has the transformation, the emerging side. Status as the main member of the traditional culture of Confucian classics, the decline in modern times, the imperial examination system, especially, the academy was finally abolished, suspension of some traditional or stale ideas and principles in the minds of the people gradually fade, disappear, natural science, school, drama, painting, and many other new department, civil rights and equality spread of new ideas, standard, such as history, literature, departments such as the introduction of new ideas and methods. These changes and conflict the inheritance of traditional craftsmanship will be an impact. When zhang hao handle in jingdezhen contented industry school when they met a lot of resistance, the town of jingdezhen Mr ShiWenMo written on the principal of "Jiang Xitao industry, and the float saddle county pottery as" mentioned: "around $1933, \ldots$. In nanchang met with zhang hao,.... Zhang hao won't get home I finish kiln, said that soup have light to sell jingdezhen property, and complaining. Zhang hao said 'jingdezhen is no way, only know that wood, not burning coal, there is no future for the contented industry, contented industry education also has no future.' I understand, he did in jingdezhen ceramic reform, do ceramic education, met great resistance, perhaps this is not located in jingdezhen ceramic school cadre in rao states." Xu Zhenshou in its "province county tao office and provincial tao designed" the article also wrote: ".... Why don't province of contented industry school located in producing porcelain city of jingdezhen, the founder of the modern vocational education in our country in 1914 huang yanpei in jingdezhen examines the vocational education, in its "examine its education notes" said 'jingdezhen porcelain making, hidebound cannot change, worry is improved, manual techniques should be eliminated without DanFan, due to fit in with the boycott is one of the potential, moved to avoid it.' "zhang hao said: jingdezhen only conservative, against improvement, only wood, is not willing to coal burning, contented industry development prospects, ceramic education also has no future. "From Mr ShiWenMo written this sentence, and in the investigation notes huang yanpei, we can infer that the difficult process of ceramic education and contented industry reform, jingdezhen ceramic education is difficult in the cracks of traditional and modern development. 


\section{The traditional art inheritance patterns and new technology development of conflict}

In China's feudal society, handicraft industry by rural sideline gradually transformed into independent production department, the original form is in the government, these craftsmen are called officer artisan, the officer artisan is, in fact, the work of the imperial family slave, for their free labor, but the craftsman is exempt from taxation. As a result, these craftsmen in order to keep your job, never will easily skill to outsiders, because even think that "married daughter, pour out the water" skill is only allowed to preach a man not female, so that makes generations down from generation to generation family heritage, making skills, family. Although this form of education to some extent to promote the art of the study, summary and improvement, and so on appear constantly new forces, and even reached the realm of "green and is better than blue", to some extent, the traditional way of teaching skills by hand to the ancient plays a positive role in promoting the development of handicraft industry, but because of its lack of horizontal communication, plus a number of reasons, some skills are often easy to lost, restricting the development of ceramics. We should see that in the presence of exploitation and oppression of feudal society is a difficult problem, especially at the end of the opium war, on the one hand, as the bud of capitalism, potter book door and GongYi thoroughly collapse in the early qing dynasty, craftsmen who serve industrial production "as price to value, the officer of the people but city", potter book door into individual worker or self locking factory owners. In pursuit of profits, these craftsmen DaiTu gives art must expand production capacity. So, ceramic art education from the father and son and to relationships, " $\mathrm{t}$ " is mentioned is second only to the status of "father", the so-called "emperor", "a day for the teacher, lifelong for father", etc., are to maintain the dignity of the teacher's principle. In general, do not master to disciple as a child, only supply room and board. If in three years of apprenticeship, the first year is dedicated to family fatigue; In the second year to learn skills to get started; After the third year of his apprenticeship, still need to master to work without pay for a year, and hosted a banquet for the industry bigwigs to testify, allowed to hire club. For future livelihood, reduce competition, be the master often for a stunt take security, not teach disciples. Can gain and apprentice born craftsmen skills, but also only rely on their own hard groping and assiduously, to be successful. Introduces, on the other hand, the Chinese people realized that western science and technology developed and powerful, some people began to attach importance to science, focus on science and technology to promote industrial and rejuvenating the country, which makes the traditional way of teaching skills is more and more not adapt to the development of productivity and production relations, necessarily promote the rise of new, in order to meet the needs of social development, cultivating new technical personnel's schools gradually born lucky, traditional mentoring, father and son are not adapted to the needs of the development of technology.

\section{The diversification of consumption behavior make traditional porcelain can't satisfy the market demand}

In ancient times, craft products occupying all aspects of people's life, there is no doubt that the traditional handmade porcelain is needed for People's Daily life. As the xinhai revolution caused by the regime change, the change of modern social politics, economy, science and technology, the self-sufficient natural economy is broken, porcelain making machine from under the industrial society has the market, it will have to let a person think, what causes this market gap? First of all, the following a few big problems with the traditional hand-made porcelain: first, the quality and supply of raw materials; Second, the level of processing technology; Third, the spirit of the economic and production information connectivity; Fourth, the advanced production management system. Second, the traditional manual porcelain can't satisfy the market demand: on the one hand, the diversified development of modern lifestyle and consumer behavior makes the traditional manual ceramic products immediately lost market; Since modern times, on the other hand, western life products continue to enter China, then called machine made piece goods, box of matches, lights, lights, and so on. Brought by the development of science and technology they occupied the city market, traditional China no longer get the favour of people, the traditional manual porcelain production must be 
marginalised. Into the modern times, influenced by western thoughts, people living in the development of traditional and modern period, people's consumption behavior also appeared diversified development, the development of consumer behavior is restricted by many factors and is not the same, such as the spending power, consumer interests, hobbies, consumer's age, political, economic and cultural conditions, environment, etc., especially in the modern society is in the direction of world integration and diversified development, the diversification of consumer behavior to adapt to the trend of The Times and has the characteristics of The Times. With the improvement of China's economic development and national income levels, after meet the basic material needs, people more and more attention to the quality of life, the demand for arts and crafts are not limited to a high level of people, ordinary citizens are increasingly obvious, just in the process of consumption of the arts and crafts for their quality and appearance of the products have different requirements. Such as the China buying groups, with foreign tourists and the intellectuals, ordinary citizens and personnel engaged in art design, they when buying porcelain requirement for porcelain has the very big difference, foreign visitors may prefer the traditional Chinese porcelain, ordinary citizens may choose porcelain, in order to achieve the purpose of practical art designer is relatively higher.

Rapid economic development has brought the material life level enhancement, as a result, people consumption idea has changed a lot, now the people is not only meet the basic material needs, especially upper-middle classes more society is the pursuit of life taste and quality of life and spiritual needs, especially pay attention to edify sentiment. Porcelain for them is not only as a practical, satisfy the spiritual taste more of a collection. The change of consumption idea makes method including blue porcelain was introduced sensation international, especially in the high-end crowd rushed to collect. They buy blue porcelain is not to buy to use, but as a decoration, make interior decoration to show the air of elegance. And for general consumption of young people, they when choosing products have their own personalities tend to choose according to be fond of, especially DIY fashion products became after 80 young people's choice, they choose the first element of product is not the quality of the product, but a creative, even buy daily products just decoration instead of actual use, they are willing to pay for it. This kind of consumption idea change requires that we in the design of ceramic products tend to consider first is creative, namely a differnce.

By visible on consumption and aesthetic idea is along with the development of economy, science and technology and constant development and change, there are differences in different age completely, since modern times, the feudal society gradually is broken, people thirst for freedom, equality, the pursuit of colorful life, traditional manual porcelain has been basically can't satisfy in life, especially the young people's lives is not satisfied.

\section{Traditional handicraft creation concept and aesthetic temperament and interest and time synchronization}

The early development of modern society, the cultural transformation appeared imbalance, traditional arts and crafts porcelain creation idea and aesthetic temperament and interest in synchronization with The Times, for example, for the development of China at that time, the market is so tight, so, some feel the world with innovation to win the market, such as fashion figure painting appeared on the jingdezhen porcelain. Some people in curiosity, and not break away the traditional idea, creates the central west mixed style. Appeared on the society and the phenomenon of mixed ancient and modern, Chinese and western, traditional crafts seems to be confused about what to do. This phenomenon not only has a great performance in the handmade porcelain industry, on the other arts and crafts products are also very prominent, such as various ge armoured professor in the "survival of the fittest: the transformation and regeneration of the traditional Chinese arts and crafts," the article said: "the modern suzhou dongshan carve patterns or designs on woodwork building, Chinese auspicious pattern and 24 filial piety, carving and Roman chapiter and Renaissance of carve patterns or designs on woodwork, unsystematic. Only embroidery unconsciously more radical change 
happened. Embroidery in ancient times with practical give priority to, dew fragrance garden 'Gu Xiu in late qing dynasty started to embroider had painted it technology, and widely circulated."

All in all, in China and the west at the beginning of the cross arm, at that time all the things are changing and constant, traditional porcelain creation idea and aesthetic temperament and interest may not synchronous development with The Times. Both traditional and modern China, each have each aesthetic feeling. Because beauty is affected by man's subjective factors, the different of The Times, people have different aesthetic consciousness. In a certain period of the aesthetic tendency is not created, and it is rooted in a specific era, however, an era of aesthetics is not only with the era of social politics, economy, culture, also with the era, the development of science and technology have a direct link to the modern high-tech products not only to pursue the product external form; More seeks to maximize the benefit of technology and market demand of consistency and coordination; Also want to pursue technology, exquisite technology products. Technology development to product batch of industrialization, the product broke the traditional manual production without the same aesthetic, but also can form a unity in the form of beauty.

Aesthetic changes with The Times change and change, of course, the change of the aesthetic is also subject to various factors, such as the development of science and technology, the change of lifestyle, values and world view change and so on, before in modern times, of primitive simplicity is heavy and complicated, for beauty, into the United States, west of modern began in the $60 \mathrm{~s}$ with a simple for the United States, after $80 \mathrm{~s}$ began to the pursuit of flowery, while contemporary is keen on the pursuit of personalized and uniqueness, and accompanied by the wind of restoring ancient ways, restoring ancient ways, of course, this is not a traditional analog blindly, but on the basis of the traditional innovation to form the uniqueness and personalization. From the point of ceramic creation, manual lasting appeal and aesthetic respectively reflect mechanical hand industrial age and mechanical production the aesthetic characteristics of The Times, with the development of the design and focus of misconduct, manual and mechanical porcelain product is different, his taste, the key point is how to attract eyeball. Today is a pluralistic era, different consumer groups, the aesthetic is different, like traditional restore ancient ways, like contemporary feeling extremely strong, have a like grotesque variation and so on, and ceramics in the creation of then give yourself what kind of consumer groups, positioning from location to determine the design style. Visible, the change of the aesthetic idea is the direct impact of ceramic design.

\section{The traditional handicraft and modern life style and mode of production of separation}

Chinese traditional handmade porcelain is mainly under the condition of self-sufficient natural economy, it gradually in modern decline and industrialization is the direct cause of the social life from, the way of traditional arts and crafts to be able to continue to develop, must adapt to the demand of the modern way of life.

From the beginning of the 20th century, the Chinese way of life by the western industrialization and high-tech development, the influence of comprehensive changes have taken place in the daily life of people, the Chinese people's life from the pursuit of natural simple turning to "westernization", such as from the 20th century western architecture, western-style clothing, the west from the bike, steam train and so on, until the mid $80 \mathrm{~s}$ after the reform and opening up, Chinese life from the "subsistence" to "well", "FuYuXing", westernization trend accelerated. Household electrical appliances has gained popularity, living environment is also constantly improving, more and more private cars, the rapid development of expressway and the information industry developed unprecedentedly. The food and clothing live line change brought about the change of lifestyle, therefore, there is no doubt that people's values, aesthetic, time space view which also changed, high-tech production of new industrial products for the rationality of the design and use and gradually become the necessities of People's Daily life, so the traditional handmade porcelain gradually out of the people's living needs of the mainstream status and exist as an ornament, so it was a sharp drop in demand. Visible, change the 
way of life will inevitably cause the contraction of traditional manual products, this is an inexorable law governing social development forward.

In the ' $50 \mathrm{~s}$ and' $60 \mathrm{~s}$ of the 20th century, the traditional craft, experienced a rare Renaissance period, under the direct guidance of the government departments at various levels, instead of the scattered individual workshops under collective ownership, to set up arts and crafts college talent and have two ways to cultivate successor. Under the planning of foreign trade and economic leverage, traditional craft into the flowers of spring. But in the process of economic system to market-oriented, many factory's difficult to maintain, or even closing their doors. And individual workshops gradually rise again. Handicraft production is given priority to with manual, product design and production can be done one by one, totally different from industrialized mass production, often in material technology. Clustering of flow process and rank wage individuals create the enthusiasm of submerged in the "pot", in the new economic system must be in trouble. The result is a large amount of solid products by industrialized mass production, such as daily-use ceramics, furniture; A small amount of special arts and crafts by workshop work, such as jewelry, gold and silver jewelry and so on, the polarization phenomenon. This is very obvious way of traditional handicraft and modern way of life and production separation results.

\section{The change of traditional porcelain making craftsmen}

Craftsmen's recent history of social status have changed a lot, with "traditional craftsmen" a significant difference between the two. "Traditional craftsmen" is the laborers engaged in traditional handicraft production, mainly refers to the family, workshops, and manual labor in factory technical workers, so they are often and said "workers" or "worker". Traditional porcelain making craftsmen often have three big distinction: a adopted for the artisans, much by handing down of intellectuals; Secondly, skilled workers, artisans, adopted is collected for the craftsman; Three for the professional community under the civil division of professional, there is a clear tutorial system and sacrifice to yili. Look from the labor form, mainly by the city workshop traditional craftsmen craftsmen (artisan cadastral system abolished before also said government craftsmen), rural household producers (including succeeding family workshops), free between urban and rural specialized craftsmen (including later in the manual workshop to hire craftsmen) of three parts.

In modern times of jingdezhen porcelain making "craftsmen" in labor means, lifestyle and status is different from "traditional" porcelain craftsmen, namely their forms and roles on porcelain making technology has the obvious change. For jingdezhen this porcelain making group we can from the Angle of porcelain making "craftsmen" social stratification, to better understand, though, on the whole, they are engaged in the porcelain, but the group's internal social relations is not uniform, the vast majority of them are ordinary porcelain craftsmen, of which only a small part after sweep up the top of the society, the porcelain in the elite status.

\subsection{Porcelain craftsman role of division of Labour}

A role reflects the certain social status. In jingdezhen, the porcelain making craftsmen there is some connection of the division of labor and gender. Jingdezhen porcelain making craftsmen's status is just the external manifestation of gender roles, is people's position in the system of social relations. Jingdezhen porcelain making has 72 working procedure, so the division of very fine, men, women and children are different, such as blocking, fettling is some experienced men live, their craft is exquisite, the majority is blocking was born at a young age, of course, there are a lot of this line is a young apprentice in schooling, fettling is a very fine work, requires patience, especially in some small things; "Red" on the other hand, mostly are done by women, especially the color in pastel mostly by experienced, crafts fine female painters, painting type techniques such as peony, kung fu is in place, otherwise it is hard to reflect the level of the bud; Composition and writing is being done by people with knowledge of culture; And abrasive, pug etc. This is not so with the mind of live mostly done by the apprentices. 
According to different porcelain making technology, the system porcelain craftsmen on the division of roles have obvious differences, according to the division of labor is different, its social status also have very big difference. Like round class craftsmen are male, artisan division of very fine, cooks, apprentice, billet, glaze work, work, work blank, cover, etc. Cover and an apprentice in a secondary position, to do the most work, and the billet and the glaze is crucial, because the division of the difference between them, the boss treat their treatment is also different. To cut class of organization, the carving cutting and antique two industry, devoid of a certain, such as needle spoon and spoon the second industry, belongs to the family industry, more organizations in order to model the vice of counting, about three models, available blowing glaze one work, and blocking one; Six deputy model, available blowing glaze, add one odd jobs. Burn in the ceramic industry workers points do with hired two long, long do workers have a 荘 industry, heavy industry, work, play big hammer, collect sand mo work, sagger, small hand, and copy the worker, cover, by which he hired on a yearly basis, according to burn to value, each time each wage binary three corners; Spread a hired man have three and a half, and two and a half, chip box car worker, porters, steward, the red half, ink half shares, the number of odd jobs, apprentice, if, scattered by the hired man long do temporary to hire workers, factory owners not to pay, only by do, whether to stick to long, the stick to roam. In addition charge four people, pay a total of three hundred yuan a year, the two porters, annual salary total and yuan, are paid by the owner, the board and lodging, no matter any workers, are supplied by the owner.

Above fields artisans on the basis of different position and the role of division of labor, wages have difference: firstly, coloured drawing or pattern of industry organization, the research is expected to work cooperate and painters, and which shall be the amount of workers without a certain average month value is 20 yuan, at least, only a few yuan, the most expensive, is particularly fine skill painters, regardless of the salary, but according to the kinds of coloured drawing or pattern, the number of how many about values. Secondly, sagger every factory workers are at least three people: 1, push the workers, from seven yuan per month; 2, earthwork, month ten yuan. 3, done on cartridge goldsmiths, 15 yuan, their accommodation are supplied by the owner. Thirdly, the ground grass industry organization, at least the whole grass, packaging, odd jobs, backpack and other workers, each month to differ to micro, about ten yuan, its biggest business, but also hire workers and 30.

\subsection{The change of social status}

Jingdezhen porcelain making craftsmen's recent history is mainly manifested in the change of the social status of the craftsman position of equality and the improvement of women's status. In modern times, as against the oppression and exploitation, successively with capitalist industry workers strike struggle again and again. This strike struggle, local called "style".

This "style" struggle for worker status has been improved. In addition, jingdezhen, said there were many walls, these bad habits is the boss in order to maintain their own interests. Due to the government for a long time to take a laissez-faire, jingdezhen porcelain making porcelain making for pie, between boss and craftspeople status inequality between the craftsmen. Du Chongyuan after come to jingdezhen reform some feudal rule, makes the craftsman achieved truly equal status with the boss. Specific displays in: first, to cancel a kiln systematically, which is no longer a kiln to buy "seat" potter boss money. Jingdezhen dominated by big potter plant, not only its kiln to kiln workers wages, on the contrary kiln workers need to pay a sum of money to trade, the so-called "buy position", how much money depending on the level and location of the kiln. Most was carried pile, billet, and copy, second second give half, three and a half, small armrest. Kiln workers pay a "buy" after the money, just can have the right to work in plant. And their labor income, it is to do a burning porcelain blank claim, do pay certain billet in addition to the potter family clinkering fee (money), but also spend "buy", in addition, whenever in May and July half, year-end, cartridge work must be made to the grey door boss ask for the "basket". This obviously exist on their status inequality. Du Chongyuan cancelled this inequality "buy" money, also no longer to take burning porcelain kiln homes of billet door to ask for the so-called "section, drinks, blowing meat, top hat money" and so on. Second, cancel the limit board first, namely how much work do daily billet board, should be depending on the 
business situation, do less business is poor, good business is to do more, do more more money. No longer limited to the grey door boss as before, truly achieve the work freely.

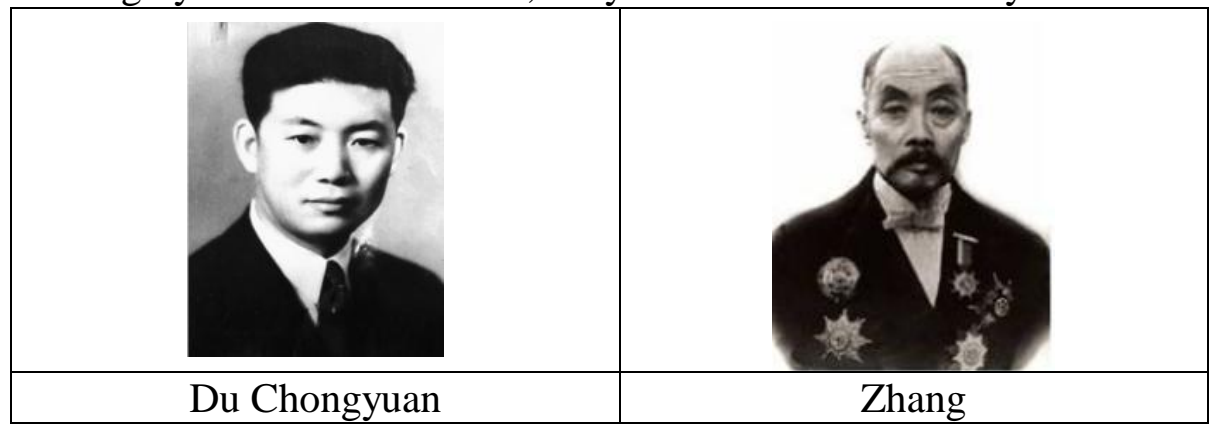

The liberation of the modern period of jingdezhen workers really are "red" women, they are no longer is oppressed by the boss, have the right to the freedom of my own work and the education. "Red" women's work, can be roughly divided into two parts: the part is working in his shop, don't go out his helper, another part is out for help, hired by the owner. In - a large red store, often is the combination of a family, brother, sister-in-law, son, daughter-in-law, daughter, nephew and niece are in a shop, in the common labor, increase the affection. Even employed women, also have this or that kind of relationship with the shopkeeper, or a family or relatives, or friends, or by the relevant people to come, they like at home, so don't usually oppressed. And their wages, mostly in the piece, cannot measure, in today's currency shall be calculated on silver dollar. Each painting red women's income, enough to maintain the life of two people. Painted red, therefore, become a part of the source of life, and promote the market prosperity role, makes them have more voice in the domestic economy. The vast majority of modern painting red women before and had not been education, limited knowledge level, conformism, rarely invention, the painted porcelain art stagnation. Jingdezhen ceramic education reform created after the women's college, many women can enter the school learning culture knowledge. Had the knowledge, they are "red" this skill is no longer purely mechanical copy, but with creative. Their work also can sell for higher price, it virtually enhanced women's status in society.

\subsection{The craftsman to improve social living conditions}

Under the modern jingdezhen porcelain industry the lives of the workers is very poor, from the aspects such as food, clothing, shelter, transportation, to talk about past ceramics of the workers' living conditions.

The vast majority of the ceramics workers wearing clothes is made of white cloth. When the day is cold, also can only wear two thin clothes, winter wear is winter jacket. At that time, porcelain making craftsmen often circulated a song in December. A rainy day, most of the craftsman no rubber shoes to wear, in warm weather is generally walking barefoot, comes at a time when the weather was cold when it wear a pair of "dry wet shoes. Porcelain industry workers used to cook a meal to eat rice is usually a very rough rice, rough rice not only, and I often eat gone mouldy meters, the so-called "japonica neck red". Meat, not to mention, every 10 genius have a meat to eat, and the time for purchasing 4 each two (one kilo for 16, two systems). Many live in workshop single in jingdezhen porcelain making craftsmen upstairs, with two stools and billet material plate into bed. In the cold, the boss gave a little straw mattress. And porcelain industry of environmental sanitation, not to mention the workers often be mosquitoes, bugs, fleas, and infectious diseases from time to time.

Engaged in the heavy work of women workers in porcelain is less, factory is mainly engaged in the needle can implement, painted porcelain spoon, ash, etc. Women's social status is extremely low, cause worse their lives. As women have children without maternity leave, maternal postpartum and no extra nutrition, maternal even meal can not even eat the boss. Even so the boss will deduct the pay of maternal. The fate of the female workers.

The prophase and metaphase stages above are some modern folk porcelain craftsmen life situation. By the end of modern, under the reform of the Du Chongyuan craftsman living conditions improved. It is administration of contented industry after the founding, because Du Chongyuan except for the 
revitalization of jingdezhen porcelain has adopted a series of improvement measures, at the same time also to improve workers' spiritual life and material life have made some efforts. On the one hand is the administration has to do with workers training, cultural popularization education for workers. Workers trained by the recruit workers from 40 or 50 people, use of spare time to learn every day night. Students are: (1) the content of the common sense, singing (2), (3) literacy, etc., the focus is on the workers to instill in students generally life common sense, the faculty by the form of the students as the teaching experience. Contented industry administration bureau site, located in the royal plant site, contented industry management station is equipped with open-air speech field, club, etc. In the second half of 1935, the administration will this place turned into open lecture, used to play regularly, songs, Peking Opera, etc.; Speech to the crowd all kinds of social problems and current affairs report; Sometimes please "celebrities" in the speech of the town in society. In addition, the administration also often organize large-scale party workers, bring your own there is a small film projector, often foreign machine porcelain making film; Sometimes some drama rehearsal, content is about porcelain making. Workers becoming to the improvement of the spiritual life greatly promote the development of jingdezhen porcelain., on the other hand, due to a group of industrialists such as through Du Chongyuan improved ceramics, opened up a new situation for the jingdezhen porcelain, has led to a new development once get depressed market of porcelain, porcelain sales growing. To improve the workers' wages, thus improve their material life, is no longer like before, do not have enough to eat wear not warm.

Contented industry authority, adopt various ways to make the workers' spiritual life and material life rich and colorful. Make the workers to have confidence and ability to do porcelain making career well. The development of jingdezhen porcelain undoubtedly played a great promoting role.

In modern times jingdezhen porcelain making handicraft workers labor conditions, without any labor protection measures, even without any protective equipment and health equipment. Porcelain workshop without any ventilation, cooling, heat and dust removal equipment, many handicraft workers in poorly ventilated room work, workshop workshop are old-fashioned houses, even the window also have no, or only open window of a bull's eye. So damp, dust flying everywhere, poor working conditions of porcelain workshop, and lost the normal development of the conditions of child labor, adult workers also creates a lot of occupational disease, anemia, tuberculosis, diseases such as heart disease, hepatitis, edema, and afflicted them.

In view of the above fact, contented industry administration efforts to improve production workers to do the following:

First of all, the administration of contented industry on the one hand, called kiln, do on behalf of the billet, and labor parties to plant, put forward the unified burn fees, wages and formal rules. In addition to the potter, workers and billet are reasonable and convenient. On the other hand, reform the kiln. Administration of strict rules kiln body size, shall not exceed 12 meters. Those who maintain cramps heavier every year, must be reported to authority for approval in advance, by the bureau to send after measurement. Meets specifications, the vouchers to build kilns, must begin to cramps, the measures to reverse the expanding kiln body at the time the kind of chaos control. At the same time, the design of mines, reduce cost and shorten the time of kiln, reduce long-term night stay up kiln kiln workers bring to their physical and mental health.

Second, the administration introduced a more advanced production technology and machinery. In this case, the workers can learn advanced machinery production operation technology. By improving their proficiency in use of mechanized operation, on the one hand can make strong manual labor conditions and bad porcelain making environment improved, on the other hand also improves the production efficiency.

Throughout modern jingdezhen porcelain industry of economy, trade, education, artisans, and many other aspects of life and production, it is easy to see: the period in foreign countries, new ideas and industrialization of jingdezhen porcelain porcelain making technology, under the influence of company system reform actively, vocational education to develop the industry, expanding China trade, both at home and abroad are successfully realized the modern transformation of traditional porcelain 
making way. New ceramics company instead of the plant, the old school education gradually replaced by a new porcelain industry school, is to break the traditional feudal ideology, and porcelain making concept is deeply rooted in the hearts of the people of science and technology, etc., all these aspects of transformation to modern times jingdezhen's porcelain has injected new vitality. In its own development at the same time, also, porcelain, and so did the jingdezhen economic, social and cultural development and progress.

\section{Conclusion}

Modern social system, culture, ideology, economy, science and technology and the changes will affect the development of the transformation of China arts and crafts, people's values, aesthetic idea, the concept of space-time has had the fundamental change, needed for food and clothing live line, by mainly relying on traditional manual products rely on industrial products, because of industrial product quality and cheap, and fine workmanship. How to adapt to this kind of product relies on shift, make the product manufacture to batch and the production, the product of inheritance and inevitably from the teacher and pupil, father and son to school uniform style of teaching. Therefore, it can be said that the birth of ceramic school and establish is the inevitable result of social development.

\section{Acknowledgements}

Xiu-mei wu, female, doctor of design art, in fuzhou, master instructor, research direction: the art of design principle, industrial design and theory, ceramic art design and theory.

This paper is the jingdezhen ceramics university center for collaborative project: "jingdezhen ceramic art education from the evolution of modern times to contemporary".

\section{References}

[1] xiu-mei wu: the inheritance and change - jingdezhen porcelain development research of the republic of China, Beijing, guangming daily press, 2012, 5 .

[2] xiu-mei wu: the traditional handicraft culture research - ceramic hangzhou fan, for example, Beijing: guangming daily press, 2013, 5.

[3] zhen-fan wan, Lin Songhua editor: studies of modern times social transformation in jiangxi, Beijing: China social sciences press, 2001.

[4] XiChuan performance: "the classical works of design art anthology, nanjing: southeast university press, 2002. 